\title{
Pengaruh Pengetahuan Investasi Terhadap Minat Mahasiswa Berinvestasi di Galeri Investasi Perguruan Tinggi
}

\author{
Lukman Hidayat $^{1}$ Nusa Muktiadji2 Yoyon Supriadi $^{3}$
}

DOI: https://doi.org/10.36339/jaspt.v3i2.215

\begin{abstract}
The Higher Education Investment Gallery was established to increase the number of investors. Investment interest can increase along with increasing investment knowledge. The purpose of this study was to analyze the influence of Capital Market Knowledge, Knowledge of Investment Instrument Types, Knowledge of Investment Profit Levels, Knowledge of Investment Risk Levels and Basic Knowledge of Stock Assessment on the Interests of Students Investing in the Investment Gallery. The study was conducted on 200 Student Members of the STIE Kesatuan Bogor Investment Gallery in May - July 2019. The results showed that Knowledge of Investment Profit Levels and Basic Knowledge of Stock Rating had a positive and significant effect on student investment interests.
\end{abstract}

Keywords: investment knowledge, investment galleries, student interests, capital markets

\begin{abstract}
Abstrak
Galeri Investasi Perguruan Tinggi didirikan sebagai bagian dari langkah meningkatkan jumlah investor dari kalangan mahasiswa. Peningkatan Minat berinvestasi terjadi seiring dengan peningkatan pengetahuan investasi. Tujuan penelitian ini adalah menganalisis pengaruh Pengetahuan Pasar Modal, Pengetahuan Jenis Instrumen Investasi, Pengetahuan Tingkat Keuntungan Investasi, Pengetahuan Tingkat Risiko Investasi serta Pengetahuan Dasar Penilaian Saham terhadap Minat Mahasiswa Berinvestasi di Galeri Investasi. Responden Penelitian ini sebanyak 200 orang Mahasiswa Anggota Galeri Investasi STIE Kesatuan Bogor pada bulan Mei - Juli 2019. Hasil penelitian memberikan kesimpulan Pengetahuan Tingkat Keuntungan Investasi dan Pengetahuan Dasar Penilaian Saham berpengaruh positif dan signifikan terhadap minat berinvestasi mahasiswa.
\end{abstract}

Kata Kunci: pengetahuan investasi, galeri investasi, minat mahasiswa, pasar modal

\section{PENDAHULUAN}

Dibandingkan dengan Negara lain, minat masyarakat Indonesia untuk melakukan investasi di pasar modal terbilang cukup rendah yaitu berjumlah $0,15 \%$ penduduk
Program Studi Manajemen Pemasaran Sekolah Tinggi IImu Ekonomi Kesatuan, Jalan Ranggagading No. 1 Bogor Indonesia 16123

\section{EMail}

lukmanhidayat@stiekesatua n.ac.id

$$
\begin{array}{r}
\text { Submitted: } \\
\text { Agustus } 2019 \\
\text { Accepted : } \\
\text { September } 2019
\end{array}
$$

JAS-PT

ISSN 2580 P

ISSN 2580 - 5339

ISSN 2620 - 5718

Volume 3

Nomor 2

DESEMBER 2019

Hal $63-70$

FORUM DOSEN INDONESIA 
Indonesia (Pajar, 2017). Galeri Investasi didirikan oleh PT Bursa Efek Indonesia bekerjasama dengan berbagai perguruan tinggi sebagai salah satu langkah menjaring investor-investor baru dari kalangan mahasiswa. Tujuan pendirian galeri investasi untuk kalangan akademisi adalah sosialisasi, edukasi dan sejauh mana mahasiswa mampu mempraktekkan teori yang dipelajari dalam perkuliahan serta mendukung kegiatan penelitian. Membangun minat mahasiswa untuk berinvestasi diperlukan langkahlangkah pendahuluan yang mendorong munculnya minat tersebut. Salah satu faktor penentunya adalah tingkat pengetahuan. Halim (2005) menyatakan bahwa untuk melakukan investasi di pasar modal diperlukan pengetahuan yang cukup, pengalaman serta naluri bisnis untuk menganalisis efek-efek mana yang akan dibeli. Pengetahuan yang memadai sangat diperlukan untuk menghindari terjadinya kerugian saat berinvestasi di pasar modal, seperti pada instrumen investasi saham.

Rumusan Masalah penelitian ini adalah Bagaimana Pengaruh Pengetahuan Pasar Modal, Pengetahuan Jenis Instrumen Investasi, Pengetahuan Tingkat Keuntungan Investasi, Pengetahuan Tingkat Risiko Investasi dan Pengetahuan Dasar Penilaian Saham terhadap Minat Berinvestasi Para Mahasiswa di Galeri Investasi.

\section{METODOLOGI PENELITIAN}

Tabel 2 Distribusi Frekuensi Responden Berdasarkan Karakteristik

\begin{tabular}{llcc}
\hline & Karakteristik Responden & Frekuensi & $\%$ \\
\hline Jenis Kelamin & Laki-laki & 64 & 32.0 \\
Usia & Wanita & 136 & 68.0 \\
& 18 tahun & 2 & 1,0 \\
& 19 tahun & 62 & 31,0 \\
& 20 tahun & 92 & 46,0 \\
& 21 tahun & 29 & 14,5 \\
& 22 tahun & 5 & 2,5 \\
& 23 tahun & 7 & 3,5 \\
Kelas & 24 tahun & 1 & 0,5 \\
& 25 tahun & 1 & 0,5 \\
& 26 tahun & 1 & 0,5 \\
& 4 MK A P & 25 & 12,5 \\
& 4 MK B P & 9 & 4,5 \\
& 4 MK C P & 11 & 5,5 \\
& 4 MK D P & 11 & 5,5 \\
& 4 MK A K & 25 & 12,5 \\
& 4 AK A P & 38 & 19,0 \\
Semester & 4 AK B P & 25 & 12,5 \\
& 4 AK C P & 29 & 14,5 \\
& 4 AK D P & 27 & 13,5 \\
& 4 & 199 & 99.5 \\
& 6 & 1 & 0.5 \\
& Manajemen Keuangan - & 81 & 40.5 \\
& S1 & 119 & 59.5 \\
\hline
\end{tabular}

Sumber: Data Primer Diolah, 2019

Penelitian ini dilakukan pada bulan Mei - Juli 2019 terhadap mahasiswa yang tercatat sebagai anggota Galeri Investasi STIE Kesatuan. Populasi dalam penelitian ini adalah mahasiswa Program Studi Akuntansi dan Manajemen Keuangan STIE Kesatuan Strata 
1. Teknik analisis data yang digunakan dalam penelitian ini menggunakan analisis korelasi dan regresi berganda.

Responden Penelitian ini adalah 200 orang mahasiswa yang menjadi Anggota Galeri Investasi STIE Kesatuan sejak semester awal. 68\% Responden berjenis kelamin wanita dan $32 \%$ responden berjenis kelamin laki-laki. Usia responden antara 18 tahun sampai dengan 26 tahun. $46 \%$ responden berusia 20 tahun dan $31 \%$ berusia 19 tahun, sisanya tersebar pada tingkat usia lain. Responden tersebar di sembilan kelas yang berbeda baik di kelas reguler atau pun kelas karyawan/ekstensi. Mayoritas responden adalah mahasiswa kelas reguler. 59,5\% responden merupakan mahasiswa program studi Akuntansi - S1, 40,5\% adalah mahasiswa program studi Manajemen Keuangan S1. Mahasiswa di kedua program studi tersebut telah memperoleh pembelajaran tentang pemahaman dasar dan mekanisme berinvestasi di pasar modal, termasuk prinsip dan manfaatnya.

Uji Kualitas Data

Sebelum dilakukan analisis data dalam rangka mengetahui pengaruh variabel Pengetahuan Investasi terhadap Minat Berinvestasi, terlebih dahulu data dianalisis untuk mengukur kualitasnya melalui uji validitas, uji reliabilitas dan uji asumsi klasik.

a. Uji Validitas

Uji validitas dilakukan atas 4 indikator (variabel Pengetahuan Pasar Modal), 4 indikator (variabel Pengetahuan Jenis Instrumen Investasi), 6 indikator (variabel Pengetahuan Tingkat Keuntungan Investasi, 11 indikator (variabel Pengetahuan Tingkat Risiko Investasi), 4 indikator (variabel Pengetahuan Penilaian Saham) dan 13 indikator (Variabel Minat Berinvestasi).

Mayoritas indikator dapat dinyatakan valid, kecuali satu indikator saja yang tidak valid dan dikeluarkan dari model penelitian ini yaitu : Indikator ke-10 dalam Variabel Pengetahuan Tingkat Risiko Investasi (PTR10) dengan nilai Korelasi Pearson 0,057 dan Signifikansi 0,419.

b. Uji Reliabilitas

Uji reliabilitas dilakukan atas 48 indikator variabel penelitian ini. Semua indikator dinyatakan reliable (handal) yang dibuktikan dengan nilai Cronbach's Alpha if Item Deleted lebih dari 0,60 dengan nilai terkecil 0,832 dan nilai terbesar 0,853. Kehandalan tersebut didukung pula dengan nilai Cronbach's Alpha gabungan sebesar 0,848.

c. Uji Asumsi Klasik

Uji Normalitas Kolmogorov-smirnov menghasilkan nilai signifikansi Asymp. Sig. (2tailed) sebesar 0,691 yang lebih besar dari nilai 0,05. Berdasarkan dasar pengambilan keputusan dalam uji normalitas kolmogorov-smirnov, dapat disimpulkan bahwa data berdistribusi normal. Dengan demikian, asumsi normalitas dalam model regresi dinyatakan terpenuhi.

Uji multikolinearitas dilakukan untuk mendeteksi ada tidaknya gejala multikolinearitas antar variabel dalam model regresi. Seluruh variabel independen dinyatakan terbebas dari gejala multikolinearitas yang dibuktikan dengan nilai Tolerance yang lebih besar dari 0,10 (antara 0,543 sampai dengan 0,935) dan nilai VIF yang kurang dari 10,00 (antara 1,070 sampai dengan 1,842).

Uji Heteroskedastisitas untuk menguji terjadinya perbedaan varian dari nilai residual pada suatu periode pengamatan ke periode pengamatan lainnya, dilakukan dengan melihat pola gambar scatterplots. Dari gambar tersebut, nampak

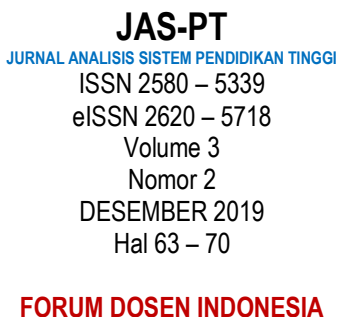

ANALISIS SISTEM PENDIDIKAN TINGGI ISSN $2580-5339$ SN $2620-571$ Volume 3 Nomor 2 DESEMBER 2019
Hal $63-70$ FORUM DOSEN INDONESIA 
titik-titik data menyebar di atas dan di bawah atau di sekitar angka nol, tidak mengumpul hanya di atas atau di bawah saja, serta tidak membentuk pola bergelombang melebar kemudian menyempit dan melebar kembali. Hal tersebut menunjukkan bahwa tidak terjadi gejala atau masalah heteroskedastisitas.

\section{HASIL DAN PEMBAHASAN}

\section{Analisis Asosiasi Pengetahuan Investasi dan Minat Berinvestasi Minat Berinvestasi}

Thimotius (2016) mengemukakan di dalam Theory of Planned Behavior, bahwasanya manusia cenderung bertindak sesuai dengan intensi dan persepsi pengendalian melalui perilaku tertentu, dimana intensi dipengaruhi oleh tingkah laku, normai subjektif serta pengendalian perilaku. Dari ketiga hal yang menentukan intensi tersebut, tingkah laku merupakan poin utama yang mampu memprediksi sebuah perilaku. Pada Theory of Planned Behavior ini juga dijelaskan bahwa niat berperilaku (behavioral intention) tidak hanya dipengaruhi oleh sikap terhadap perilaku (attitude towards behavior) dan norma subyektif (subjective norm), tetapi juga dipengaruhi oleh kontrol keperilakuan yang dirasakan (perceived behavioral control). Kontrol keperilakuan dipengaruhi oleh pengalaman masa lalu dan perkiraan seseorang mengenai sulit atau tidaknya untuk melakukan perilaku tertentu (Azwar, 2003). Karenanya niat berperilaku dapat menunjukkan perilaku yang akan dilakukan oleh seseorang. Hal ini dapat menjelaskan apabila seorang yang memiliki minat berinvestasi maka dia cenderung akan melakukan tindakan-tindakan untuk dapat mencapai keinginannya berinvestasi. Misalkan dengan mengikuti pelatihan dan seminar tentang investasi, menerima dengan baik penawaran investasi, dan pada akhirnya melakukan investasi (Kusmawati, 2011).

Ciri-ciri seseorang yang berminat untuk berinvestasi dapat diketahui dengan seberapa berusahanya mereka dalam mencari tahu tentang suatu jenis investasi, mempelajari dan kemudian mempraktikanya. Hal ini senada dengan pendapat Kusmawati (2011) yang menyatakan bahwa minat berinvestasi adalah keinginan untuk mencari tahu tentang jenis suatu investasi dimulai dari keuntungan, kelemahan, kinerja investasi dan lain sebagainya. Ciri lain yang dapat dilihat adalah mereka akan berusaha meluangkan waktu untuk mempelajari lebih jauh tentang investasi tersebut atau mereka langsung mencoba berinvestasi pada jenis investasi tersebut, bahkan menambah 'porsi' investasi mereka yang sudah ada.

\section{Pengetahuan Pasar Modal}

Pengetahuan Pasar Modal merupakan pengetahuan tentang konsep dan manfaat keberadaan pasar modal di Indonesia. Pengetahuan Pasar Modal terdiri dari pengetahuan tentang (a) Pasar Modal Sebagai Wadah Investasi Resmi, (b) Perusahaan, Masyarakat dan Kelebihan Dana, (c) Instrumen yang Dijual di Pasar Modal, (d) Pasar Modal Sumber Pendanaan.

\section{Pengetahuan Jenis Instrumen Investasi}

Pengetahuan Jenis Instrumen Investasi merupakan pengetahuan tentang jenis

JAS-PT

JURNAL ANALISIS SISTEM PENDIDIKAN TINGG

ISSN $2580-5339$

eISSN $2620-5718$

Volume 3

Nomor 2

DESEMBER 2019

Hal $63-70$

investasi yang dapat dibedakan menjadi investasi langsung (direct investment) dan investasi tidak langsung (indirect investment). Pengetahuan Jenis Instrumen Investasi terdiri dari pengetahuan tentang (a) Saham Instrumen Keuangan Pasar Modal, (b) Tempat Pembelian Saham, (c) Jangka Waktu Saham, (d) Jangka Waktu Deposito dan Obligasi. 


\section{Pengetahuan Tingkat Keuntungan}

Tujuan berinvestasi adalah untuk mendapatkan keuntungan (Syahyunan (2015:74). Pengetahuan Tingkat Keuntungan Investasi terdiri dari pengetahuan tentang (a) Dividen Keuntungan Investasi Saham (b) Pembagian Laba Perusahaan Kepada Investor, (c) Keuntungan Yang Diperoleh Dari Saham, (d) Keuntungan Lain yang diperoleh dari Saham, (e) Investasi Saham Lebih Menguntungkan, (f) Investasi Deposito Lebih Menguntungkan.

\section{Pengetahuan Tingkat Risiko}

Saham dikenal dengan karakteristik imbal hasil tinggi, resiko tinggi (high risk, high return). Artinya saham merupakan surat berharga yang memberikan peluang keuntungan tinggi namun juga berpotensi resiko tinggi (Darmadji dan Fakhruddin, 2015:10). Sikap investor terhadap risiko akan sangat tergantung kepada preferensi investor tersebut terhadap risiko. Investor yang lebih berani akan memilih investasi yang memiliki risiko tinggi, yang diikuti tingkat keuntungan yang tinggi pula. Sebaliknya investor yang tidak mau menanggung risiko yang terlalu tinggi, tentunya tidak akan bisa mengharapkan tingkat keuntungan yang terlalu tinggi (Syahyunan, 2015:75).

Pengetahuan Tingkat Risiko Investasi terdiri dari pengetahuan tentang (a) Prinsip Investasi Saham, (b) Risiko Investasi Saham, (c) Tidak Memperoleh Dividen Adalah Risiko Investasi Saham, (d) Risiko Kebangkrutan Pada Perusahaan Yang Menjual Saham, (e) Capital Loss Merupakan Kerugian Membeli Saham, (f) Pemegang Saham Pemilik Hak Terakhir Kekayaan Perusahaan, (g) Investasi Saham Berisiko Lebih Tinggi Dibanding Obligasi, (h) Risiko Investasi Saham dan Obligasi, (i) Manfaat Mengukur Tingkat Risiko, (j) Pilihan Investasi Risiko Rendah, (k) Pilihan Investasi Risiko Tinggi.

\section{Pengetahuan Dasar Penilaian Saham}

Pengetahuan dasar penilaian saham merupakan pengetahuan investor terkait penilaian terhadap saham dengan menghitung IRR, NPV, dan lain-lain, pendapatan atau laba perusahaan yang diharapkan. Uang dapat digunakan sebagai dasar dalam penilaian saham. Pengetahuan dasar penilaian saham terdiri dari pengetahuan tentang (a) Pentingnya Pengetahuan Dasar Investasi, (b) Peran Sekolah Pasar Modal, (c) Peran Mata Kuliah Teori Portofolio , (d) Peran Mata Kuliah Teori Portofolio.

Untuk mengetahui tingkat hubungan antar variabel, dilakukan uji korelasi pearson.

Tabel 3. Hasil Uji Korelasi Variabel Pengetahuan Investasi dan Minat Berinvestasi

\begin{tabular}{lcc}
\hline \multicolumn{1}{c}{ Variabel } & Korelasi Pearson & Signifikansi \\
\hline Pengetahuan Pasar Modal & 0,112 & 0,115 \\
Pengetahuan Jenis Instrumen Investasi & $0,219^{* *}$ & 0,002 \\
Pengetahuan Tingkat Keuntungan & $0,259^{* *}$ & 0,000 \\
Investasi & $0,202^{* *}$ & 0,004 \\
Pengetahuan Tingkat Risiko Investasi & $0,334^{* *}$ & 0,000 \\
Pengetahuan Dasar Penilaian Saham & &
\end{tabular}

Sumber: Data Primer Diolah, 2019

Pengetahuan Jenis Instrumen Investasi, Pengetahuan Tingkat Keuntungan Investasi, Pengetahuan Tingkat Risiko Investasi dan Pengetahuan Dasar Penilaian Saham memiliki hubungan positif dan signifikan terhadap Minat Berinvestasi para Mahasiswa di Galeri Investasi STIE Kesatuan. Hal ini terlihat dari nilai Korelasi Pearson masingmasing sebesar 0,$219 ; 0,259 ; 0,202$ dan 0,334 dengan nilai signifikansi yang kurang dari 0,05. (Lihat Tabel 3). Secara simultan, Pengetahuan Investasi memiliki hubungan positif $(0,409)$ terhadap minat berinvestasi. (Lihat Tabel 4).

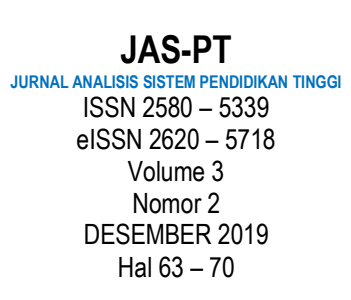

FORUM DOSEN INDONESIA 
Tabel 4. Hasil Analisis Regresi Variabel Pengetahuan Investasi dan Minat Berinvestasi

\begin{tabular}{lccc}
\hline \multicolumn{1}{c}{ Keterangan } & Koefisien & thitung $_{\text { }}$ & Signifikansi \\
\hline (Konstanta) & 25,808 & 5,360 & 0,000 \\
Pengetahuan Pasar Modal & $-0,078$ & $-0,363$ & 0,717 \\
Pengetahuan Jenis Instrumen & 0,094 & 0,535 & 0,593 \\
Investasi & & & \\
Pengetahuan Tingkat Keuntungan & 0,279 & 2,025 & 0,044 \\
Investasi & 0,093 & 1,058 & 0,291 \\
Pengetahuan Tingkat Risiko Investasi & 0,869 & 4,342 & 0,000 \\
Pengetahuan Dasar Penilaian Saham & 0,409 & & \\
R & 0,167 & & \\
R Square & 0,146 & & 0,000 \\
Adjusted R Square & 7,787 & & \\
Fhitung & & & \\
a. Dependent Variable: Minat & & & \\
Berinvestasi & &
\end{tabular}

Berdasarkan hasil analisis regresi pada Tabel 4, Persamaan yang dapat dibangun dari hasil analisis tersebut adalah sebagai berikut :
Minat Berinvestasi $=25,808+0,279$ Pengetahuan Tingkat Keuntungan Investasi $+0,869$ Pengetahuan Dasar Penilaian Saham

Di saat Pengetahuan Investasi tidak memberi pengaruh, Minat Berinvestasi Mahasiswa memiliki nilai sebesar 25,808 . Hal ini menunjukkan bahwa mahasiswa sudah memiliki minat untuk berinvestasi di Galeri Investasi.

Pengetahuan Tingkat Keuntungan Investasi berpengaruh secara positif sebesar 0,279 terhadap Minat Berinvestasi. Hal ini bermakna bahwa setiap terdapat kenaikan dalam Pengetahuan Tingkat Keuntungan Investasi sebanyak satu satuan maka akan memberikan pengaruh positif sebesar 0,279 terhadap minat berinvestasi para mahasiswa.

Pengetahuan Dasar Penilaian Saham berpengaruh positif sebesar 0,869 terhadap Minat Berinvestasi. Setiap kenaikan satu satuan pada Pengetahuan Dasar Penilaian Saham, maka Minat Berinvestasi para mahasiswa akan meningkat sebesar 0,869.

Nilai R Square sebesar 0,167 dan Adjusted R Square sebesar 0,146 menunjukkan Minat Berinvestasi para Mahasiswa STIE Kesatuan di Galeri Investasi mampu dijelaskan sebesar 16,79\% oleh variabel Pengetahuan Investasi secara bersama-sama. Sisanya $83,21 \%$ dipengaruhi faktor lain yang tidak masuk dalam model.

Nilai Fhitung sebesar 7,787 dan Sig 0,000 menunjukkan bahwa Pengetahuan Investasi secara bersama-sama mempengaruhi Minat Berinvestasi para Mahasiswa STIE Kesatuan di Galeri Investasi secara signifikan.

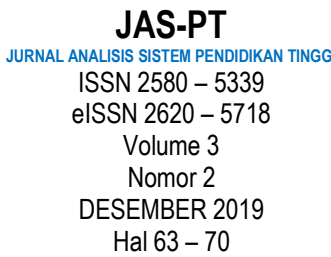

FORUM DOSEN INDONESIA

\section{PENUTUP}

Simpulan

Beberapa simpulan penelitian ini adalah sebagai berikut :

1. Pengetahuan Pasar Modal, Pengetahuan Jenis Instrumen Investasi, Pengetahuan Tingkat Keuntungan Investasi, Pengetahuan Tingkat Risiko Investasi dan 
Pengetahuan Dasar Penilaian Saham memiliki hubungan dengan Minat Berinvestasi para Mahasiswa.

2. Pengetahuan Tingkat Keuntungan Investasi berpengaruh positif dan signifikan terhadap Minat Berinvestasi para Mahasiswa di Galeri Investasi STIE Kesatuan

3. Pengetahuan Dasar Penilaian Saham berpengaruh positif dan signifikan terhadap Minat Berinvestasi para Mahasiswa di Galeri Investasi STIE Kesatuan

4. Pengetahuan Pasar Modal, Pengetahuan Pengetahuan Jenis Instrumen Investasi dan Pengetahuan Tingkat Risiko Investasi tidak berpengaruh signifikan terhadap Minat Berinvestasi para Mahasiswa di Galeri Investasi STIE Kesatuan.

\section{Implikasi Manajerial}

Berkembangnya Galeri Investasi Perguruan Tinggi ditandai dengan banyaknya mahasiswa atau sivitas akademika lainnya yang berinvestasi pada galeri tersebut. Minat para mahasiswa untuk berinvestasi sangat dipengaruhi oleh faktor pengetahuan investasi yang dimilikinya. Secara empiris, adanya pengaruh pengetahuan investasi terhadap minat berinvestasi di pasar modal pada mahasiswa FE UNY telah dibuktikan oleh Rizky Chaerul Pajar (2017). Hal ini pun sejalan dengan hasil penelitian Rima Wijayanti (2015) yang menyimpulkan bahwa Pengetahuan berpengaruh siginifikan terhadap minat mahasiswa berinvestasi Dinar.

Merujuk hasil analisis data penelitian ini, Pengetahuan Tingkat Keuntungan Investasi dan Pengetahuan Dasar Penilaian Saham merupakan pengetahuan yang harus diperkuat di kalangan mahasiswa agar minat berinvestasinya dapat meningkat. Jika merujuk pada nilai R-Square Penelitian ini, maka masih banyak faktor-faktor lainnya yang harus diperhatikan dan ditingkatkan oleh Pengelola Galeri Investasi dan Pimpinan Perguruan Tinggi, antara lain peningkatan motivasi, penjelasan manfaat investasi di pasar modal, dan penjelasan modal minimal investasi yang diperlukan.

Pengembangan Pengetahuan Mahasiswa tentang Investasi di Pasar Modal penting dilakukan untuk pengembangan Galeri Investasi Perguruan Tinggi

Untuk penelitian selanjutnya, dapat dimasukkan variabel lain yang dapat mempengaruhi minat berinvestasi para mahasiswa antara lain motivasi, besaran modal investasi, dan manfaat investasi.

\section{DAFTAR PUSTAKA}

Baihaqi, M. (2016). Pengantar Psikologi Kognitif. Bandung: PT Refika Aditama.

Darmadji T., dan Fakhruddin, H. M. (2015). Pasar Modal di Indonesia. Jakarta: Salemba Empat.

Effendy, M., Surya, T.M. and Mubarak, M.M., 2009. Pengaruh Struktur Modal Terhadap Resiko Keuangan Perusahaan. Jurnal IImiah Kesatuan (JIK), 11(1).

[Kemenkeu Rl], (2010). Master Plan Pasar Modal dan Industri Keuangan Non Bank 2010-2014. BAPEPAM LK Kementeria Keuangan Republik Indonesia

Komang Luh, I Putu Mega. (2015). Kemampuan Pelatihan Pasar Modal Memoderasi Pengaruh Pengetahuan Investasi Dan Penghasilan Pada Minat Berinvestasi Mahasiswa. Jurnal IImiah Akuntansi dan Bisnis, Vol. 10, No. 2, Juli 2015.

Halim, Abdul. (2015). Analisis Investasi di Aset Keuangan. Jakarta: Penerbit Salemba Empat

Hasan, lqbal, (2005). Pokok - Pokok Materi Statistik 2. Cetakan ketiga, Jakarta : PT. Bumi Aksara.

JAS-PT

JURNAL ANALISIS SISTEM PENDIDIKAN TINGG ISSN $2580-5339$ eISSN $2620-5718$ Volume 3 Nomor 2 DESEMBER 2019 Hal $63-70$

FORUM DOSEN INDONESIA 
Hermanto. (2017). Perilaku Mahasiswa Ekonomi di Universitas Esa Unggul Dalam Melakukan Investasi Di Pasar Modal. Jurnal Ekonomi, Volume 8, Nomor 2, Mei 2017.

Hidayat, L., Mulyana, M. and Effendy, M., 2018. Membangun Kepuasan Mahasiswa Pengguna Laboratorium Komputer. JAS-PT Jurnal Analisis Sistem Pendidikan Tinggi, 1(2), pp.93-101.

Nurendah, Y., Mulyana, M. and Muanas, M., 2018. Evaluasi dan Pemetaan Minat Studi Siswa SMA dan SMK di Kota Bogor Pada Program Studi Ekonomi Syariah. JAS-PT Jurnal Analisis Sistem Pendidikan Tinggi, 2(2), pp.83-94.

Mulyana, M., Hidayat, L. and Puspitasari, R., 2019. Mengukur Pengetahuan Investasi Para Mahasiswa Untuk Pengembangan Galeri Investasi Perguruan Tinggi. JAS-PT Jurnal Analisis Sistem Pendidikan Tinggi, 3(1), pp.31-52.

Pajar, Rizki Chaerul, (2017). Pengaruh Motivasi Investasi Dan Pengetahuan Investasi Terhadap Minat Investasi Di Pasar Modal Pada Mahasiswa FE UNY. Skripsi. Fakultas Ekonomi Universitas Negeri Yogyakarta

Purba, J. H. V., Ratodi, M., Mulyana, M., Wahyoedi, S., Andriana, R., Shankar, K., \& Nguyen, P. T. Prediction Model in Medical Science and Health Care.

Situmorang, M., Andreas, \& Natariasari, R. (2014). Pengaruh Motivasi Terhadap Minat Berinvestasi Di Pasar Modal Dengan Pemahaman Investasi Dan Usia Sebagai Variabel Moderat. JOM FEKON, 1.

Sugianto, D. (2017). Investor Aktif Pasar Modal Kini Didominasi Anak Muda. https://finance.detik.com/bursa-dan-valas/d-3426387/investor-aktif-pasarmodal-kini-didominasi-anak-muda (diakses pada 26 Agustus 2019 13:05 WIB)

Suharyadi dan Purwanto, S. K. (2004). Statistika Dasar. Jakarta: Salemba Empat.

Sukartaatmadja, I., Thoyibah, H., Mulyana, M. and Yusdira, A., 2019. PELATIHAN DIGITAL LIBRARY BAGI PENGELOLA PERPUSTAKAAN PERGURUAN TINGGI SE-BOGOR.

Sulistiono, S., Nurendah, Y. and Mulyana, M., 2019. Mengukur Minat Studi Siswa SMA dan SMK di Kota Bogor Pada Program Studi Kewirausahaan. JAS-PT Jurnal Analisis Sistem Pendidikan Tinggi, 3(1), pp.1-12.

Syahyunan. (2013). Manajemen Keuangan. Medan: USU Press.

Verawati, Eka, (2014). Faktor-Faktor Penentu yang Mempengaruhi Return Saham Perusahaan Manufaktur Yang Terdaftar Di Bursa Efek Indonesia (BEI) Periode 2008-2013. Skripsi. Fakultas Ekonomi Universitas Negeri Yogyakarta

JAS-PT

JURNAL ANALISIS SISTEM PENDIDIKAN TINGG

ISSN $2580-5339$

eISSN $2620-5718$

Volume 3

Nomor 2

DESEMBER 2019

Hal $63-70$

FORUM DOSEN INDONESIA 